\title{
PROJECT BASED LEARNING E DESIGN THINKING EM UM PROJETO DE INTERCÂMBIO
}

\author{
PROJECT BASED LEARNING Y DESIGN THINKING EN UN PROYECTO DE \\ INTERCAMBIO
}

\author{
PROJECT BASED LEARNING AND DESIGN THINKING IN AN EXCHANGE \\ PROJECT
}

José Pinheiro de QUEIROZ-NETO Marcella Sarah Filgueiras de FARIAS ${ }^{2}$ Emanuelle Lorena Teixeira CHAGAS ${ }^{3}$

RESUMO: Este artigo apresenta a integração de duas metodologias que visam o desenvolvimento das Soft Skills, integrando a metodologia de Aprendizagem Baseada em Projeto (Project Based Learning - PBL) a um método prático para a integração de habilidades e mentalidade inovadora no desenvolvimento de soluções, conhecido por Design Thinking DT. Esta integração se deu no âmbito de um projeto de intercâmbio internacional com equipes formadas por alunos de países diferentes, oriundos de cursos diversos, com outros idiomas, cultura e base de conhecimento, desenvolvido ao longo de dez semanas. Levar aos alunos a formação em Soft Skills nesta multiplicidade se tornou um desafio ainda maior por ter ocorrido em um período de pandemia. Os resultados da integração PBL-DT demonstram o grande potencial destes métodos utilizados de maneira integrada, e atingiu aos objetivos do projeto.

PALAVRAS-CHAVE: Aprendizagem baseada em projetos. Design thinking. Habilidades interpessoais.

RESUMEN: Este artículo trata sobre la integración de dos metodologías que tienen como objetivo desarrollar las Soft Skills. La idea es integrar la metodología Project Based Learning (PBL) con un método práctico para la mentalidad innovadora, conocido como Design Thinking - DT. Esta integración fue desarrollada y probada en un proyecto de intercambio internacional con equipos de estudiantes de diferentes países, de diferentes cursos, con otros idiomas, cultura y área de conocimiento. El proyecto se desarrolló durante diez semanas. Desarrollar las Soft Skills para los estudiantes en esta multiplicidad de diferencias se ha convertido en un desafio aún mayor porque ocurrió en un período de

\footnotetext{
${ }^{1}$ Instituto Federal do Amazonas (IFAM), Manaus - AM - Brasil. Professor no Programa de Pós-Graduação em Educação Profissional e Tecnológica. Doutorado em Ciências da Computação (UFMG). ORCID: https://orcid.org/0000-0003-1498-2829. E-mail: pinheiro@ifam.edu.br

${ }^{2}$ Instituto Federal do Amazonas (IFAM), Manaus - AM - Brasil. Doutoranda no Programa de Pós-Graduação Profissional em Ensino Tecnológico. ORCID: https://orcid.org/0000-0002-9408-9450. E-mail: sarah.marcella@gmail.com

${ }^{3}$ Instituto Federal do Amazonas (IFAM), Manaus - AM - Brasil. Mestranda no Programa de Pós-Graduação em Educação Profissional e Tecnológica. ORCID: https://orcid.org/0000-0003-0724-0253. E-mail: emanuelle_chagas@hotmail.com
} 
pandemia. Los resultados de la integración PBL-DT demuestran el gran potencial de estos métodos utilizados de manera integrada y han logrado los objetivos del proyecto.

PALABRAS CLAVE: Aprendizaje em base a proyectos. Design thinking. Habilidades interpersonales.

ABSTRACT: This paper is about the integration of two methodologies that aim to develop the Soft Skills. The idea is to integrate the Project Based Learning (PBL) methodology with a practical method for innovative mindset, known as Design Thinking - DT. This integration was developed and tested in an international exchange project with student teams from different countries, from different courses, with other languages, culture and knowledge area. The project was developed over ten weeks. Develop the Soft Skills for students in this multiplicity of differences has become an even greater challenge because it occurred in a pandemic period. The results of the PBL-DT integration demonstrate the great potential of these methods used in an integrated manner and had achieved the project goals.

KEYWORDS: Project based learning. Design thinking. Soft skills.

\section{Introdução}

A exemplo de países como a Finlândia, Canadá e Austrália, o Brasil tem buscado alternativas para a melhoria de seu sistema de educação profissional; entre estas está a utilização de metodologias ativas, que permitam atividades que facilitam um olhar para uma formação humana integral (BARBOSA; MOURA, 2013). Portanto, dentre as possibilidades de reinvenção do trabalho educativo, ampliou-se a utilização das metodologias ativas como caminho pedagógico na superação das dicotomias presentes no novo cenário escolar.

A educação profissional também busca por esta formação humana integral, que prepare o aluno para a vida real, como “[...] elemento estratégico para a construção da cidadania e para a melhor inserção de jovens e trabalhadores na sociedade contemporânea, plena de grandes transformações e marcadamente tecnológica”. (BRASIL, 2004, p. 7). Portanto, as práticas educativas devem envolver, além dos conhecimentos e habilidades técnicas (hard skills), os aspectos pertinentes à formação das habilidades interpessoais (soft skills) dos estudantes, sem as quais os mesmos teriam dificuldades em potencializar seus conhecimentos profissionais específicos. Além disto, uma formação orientada à inovação se faz necessária em um ambiente cada vez mais competitivo, no qual o país precisa potencializar seus talentos e fortalecer a cultura e a prática da inovação.

O Instituto Federal do Amazonas (IFAM) firmou, em 2018, um convênio com instituições nacionais, latino-americanas e europeias para o desenvolvimento do projeto 
intitulado "Latin America Practices and Soft Skills for an Innovation Oriented Network (LAPASSION)", financiado com recursos advindos do Programa Erasmus Plus da União Europeia. O Projeto LAPASSION tem como coordenação geral o Instituto Politécnico do Porto - IPP, e conta com a participação de uma instituição finlandesa (TAMK), duas espanholas (Univ. de Vigo, Univ. de Salamanca), duas chilenas (DUOC, PUC), duas uruguaias (UDELAR, DEOC) e cinco brasileiras (IFAM, IFMA, IFG, IFTM e IFsul). O projeto tem como objetivo o intercâmbio de estudantes do ensino superior, orientados por professores e parceiros externos, no qual são formados grupos de trabalho com alunos de cursos e países diferentes, para atuarem em projetos específicos, e que se dedicam durante 10 semanas para apresentar uma solução a um problema ou desafio proposto por uma empresa, organização não governamental ou instituição pública, de acordo com um tema previamente definido. O idioma oficial do projeto é o inglês.

O projeto se divide em missões que acontecem em cidades diferentes, e já ocorreu no Chile (Santiago), Uruguai (Montevidéu) e Brasil (São Luiz, Uberaba, Goiânia e Manaus). O LAPASSION Manaus, no Amazonas/Brasil, ocorreu no período de 02 de março a 08 de maio de 2020, e teve como tema geral as "Tecnologias socioambientais para a sustentabilidade da Amazônia”. Em Manaus, o projeto recebeu 08 alunos do exterior (02 Finlândia, 02 Portugal e 4 do Chile) e 06 de Institutos Federais brasileiros (Piauí, Pará, Rondônia, Pernambuco, Amapá e Alagoas). Devido à Pandemia SARS COV2, o projeto teve as atividades presenciais suspensas após a terceira semana em que o mesmo estava sendo executado.

O LAPASSION Manaus utilizou como metodologia ativa, para o desenvolvimento das Soft Skills, uma integração da metodologia de Aprendizagem Baseada em Projeto (Project Based Learning - PBL) a um método prático para a integração de habilidades e mentalidade inovadora no desenvolvimento de soluções, conhecido por Design Thinking - DT. Esta integração se mostra um processo de aprendizagem que gera alunos autônomos, que requer conhecimento e disposição do professor para atuar como mentor e, principalmente, traz consigo uma aprendizagem onde o aluno é percebido como centro do processo e atua de maneira autônoma, em um olhar para uma formação humana integral (BARBOSA E MOURA, 2013). As interações em colaboração com equipes multidisciplinares, multiculturais e multilíngue criaram o ambiente ideal para o desenvolvimento das Soft Skills, dentre as quais se pode destacar a liderança, a comunicação, a resolução de conflitos, a empatia, a ética, a flexibilidade e a gestão de equipes. 


\section{O Método Project Based Learning (PBL)}

A Aprendizagem Baseada em Projeto (Project Based Learning - PBL) surgiu em 1900, quando comprovado por John Dewey (1859-1952) que é possível “aprender mediante o fazer", quando os alunos são instigados a pensar, resolver problemas através de projetos e desenvolver-se fisicamente, emocionalmente e intelectualmente (MASSON et al., 2012). Contudo, segundo Zabala (1998), foi o norte-americano William Kilpatrick (1871-1965), baseado nas ideias de John Dewey, quem estruturou e difundiu o método de projetos, sendo o realizador prático do método, que para ele tem como pressuposto o interesse e o esforço.

Masson et al. (2012, p. 1) define a PBL como "[...] uma abordagem sistêmica, que envolve os alunos na aquisição de conhecimentos e competências por meio de um processo de investigação de questões complexas, tarefas autênticas e produtos, cuidadosamente planejadas com vista a uma aprendizagem eficiente e eficaz". Marques (2016, p. 21) acrescenta que a PBL se utiliza de uma situação-problema para motivar o estudo dos alunos, colocando estes no centro do processo ensino-aprendizagem.

Na PBL o aluno é o gerador do seu próprio conhecimento, podendo ser aplicado no ambiente da própria sala de aula ou em outro ambiente/local fora da sala de aula, realizando a quebra de paradigmas do tradicionalismo e tornando o aluno o ator principal no processo de aprendizagem, sendo o professor aquele que faz o elo entre a teoria e a prática, rompendo com a forma tradicional de transmitir o conteúdo (STAHNKE et al., 2015).

Diniz (2015) apresenta a seguinte sequência: planejamento; definição do tema; estabelecimento da pergunta problema; estruturação do conhecimento; acompanhamento dos diferentes aprendizados; avaliação e a socialização do projeto. Para a autora, a organização das atividades por projetos é fundamental para se obter resultados positivos.

Queiroz-Neto et al. (2015, p. 4-5) apresentam uma proposta de passos para a aplicação da PBL, que pode sofrer adaptações de acordo com a situação, mas que de maneira geral possui as etapas e fluxo conforme a Figura 1: 
Figura 1 - Etapas da Project Based Learning - PBL

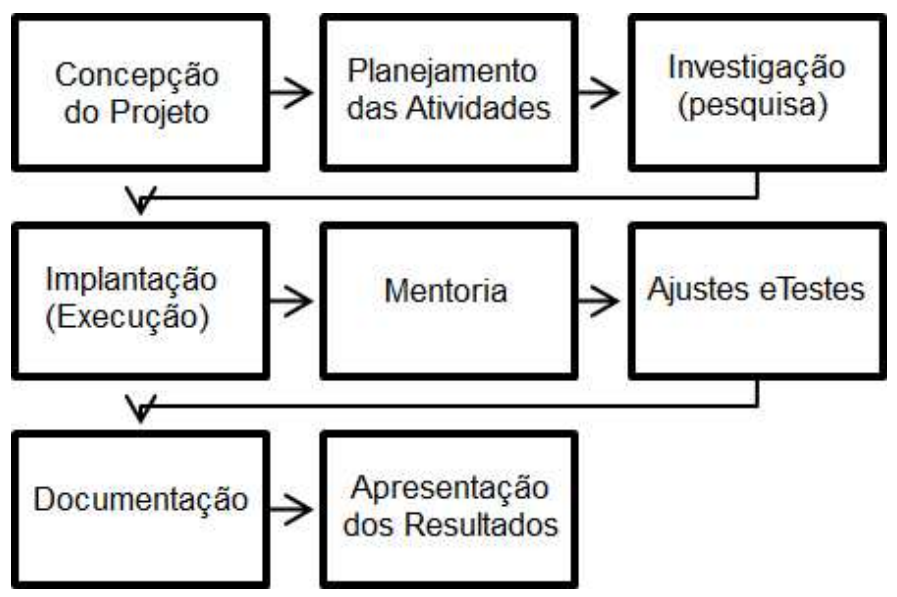

Fonte: Traduzido de Queiroz-Neto et al. (2015, p. 4)

Desta forma, entende-se que para realizar o método PBL é preciso uma organização e preparação prévia, para que os alunos, com a orientação dos professores, possam conceber o projeto, realizar o planejamento, execução, avaliação e socialização do produto final. É neste caminhar que se materializa a formação nas Soft Skills. Para Diniz (2015, p. 13), “A aprendizagem baseada em projetos estimula os alunos a adquirir conhecimentos e habilidades, possibilitando a interdisciplinaridade em torno de investigação de questões complexas".

\section{O Método Design Thinking (DT)}

O Design Thinking (DT) é um processo focado na concepção de produtos e serviços inovadores que resolvam as reais necessidades das pessoas. Para a realização do projeto adotamos como referencial Vianna et al. (2012), que apresenta o DT em três fases: imersão, ideação e prototipação. A imersão objetiva estudar o problema, suas implicações, a partir do levantamento de dados, compreensão do público-alvo, organização e análise das informações. A fase de ideação visa a geração de soluções com base nas informações da imersão que colaborem para a resolução do problema proposto; e a fase de prototipação transforma as ideias em planos de ações ou um artefato, digital ou físico, por meio de uma representação conceitual ou análoga, que se aproxime de uma versão final de um produto.

A imersão é a primeira parte do processo, em que há dois focos: levantar dados que levem ao aprofundamento e delimitação do problema, e definir o público-alvo que está envolvido na questão. A imersão se divide em imersão preliminar e em profundidade. 
A imersão preliminar é uma forma de aproximação do problema para compreendê-lo sob diversas perspectivas e definir dos limites do projeto. Além disto, o público-alvo é escutado e cria-se um entendimento inicial das necessidades a serem sanadas. Também são consideradas pesquisas, experiências e informações pertinentes que contribuam para o desenvolvimento do projeto.

$\mathrm{Na}$ imersão em profundidade o foco é o público-alvo, um aprofundamento do contexto e necessidades das pessoas envolvidas com o problema. Para isso, são realizados entrevistas, observações e registros que sirvam de insumos para pensar em soluções inovadoras.

Após a coleta e registro destes dados, ocorre uma subfase chamada análise e síntese. Os dados são organizados e agrupados de forma a indicarem critérios que irão nortear o processo criativo, ou seja, direcionar e alimentar a fase de ideação.

$\mathrm{Na}$ fase de ideação são geradas propostas de soluções que são direcionadas por meio dos critérios norteadores, oriundos da análise e síntese, de forma que atendam às necessidades mapeadas do público-alvo e respondam ao problema definido. Como resultado da fase, é selecionada uma ou mais alternativas que podem ser testadas, ou combinadas, na fase seguinte, prototipação.

A fase de prototipação tem como objetivo testar de maneira rápida, com baixo custo, a solução encontrada. O objetivo é verificar quais os possíveis erros que podem ocorrer, a relação do resultado encontrado com o meio aplicado e com as pessoas. Desta forma, altera-se o projeto de maneira mais rápida, retornando a fases anteriores para ajustes, aprofundamento de informações ou alterações do problema.

O DT tem como características ser um processo interativo, as fases estão interligadas; incremental, pode-se acrescer dados a qualquer momento do processo; e iterativo, retornar a fases que sejam necessárias, envolvendo pessoas com conhecimentos multidisciplinares e com a participação do público-alvo.

Seu dinamismo torna-o aplicável para projetos com foco em criatividade, inovação e trabalho em equipe, como no LAPASSION, e que são pertinentes com a proposta da PBL.

\section{Project Based Learning e Design Thinking integrados ao Projeto LAPASSION}

O projeto LAPASSION precisava de um dinamismo para desenvolver nos estudantes as Soft Skills, e ao mesmo tempo uma objetividade para, em 10 semanas, obter resultados tangíveis aos desafios apresentados pelas parcerias com empresas e instituições. A solução foi 
integrar a PBL, comprovadamente útil para desenvolver as Soft Skills, ao DT, um método de sucesso para pensar e desenvolver soluções inovadoras de maneira organizada e concreta.

A Figura 2 apresenta a integração da PBL e DT. Nesta a DT está inserida, como método de desenvolvimento organizando de um produto inovador, dentro do arcabouço da PBL, com suas etapas descritas na Figura 1, que se integram às etapas da DT. Com isto oportunizamos aos alunos desenvolverem autonomia, liderança, resiliência, gestão de conflitos, responsabilidades, colaboração, comunicação e senso crítico, entre outras habilidades.

Esta proposta proporciona ao estudante uma formação humana integral, contrária àquela proposta pela escola dual, na qual a educação profissional e tecnológica brasileira foi construída. Sendo assim, tem-se o entendimento da formação humana integral como aquela que gira em torno da integração de todas as dimensões e potencialidades do indivíduo no processo educativo. Essas dimensões, segundo Frigotto (2012, p. 267), “envolvem sua vida corpórea material e seu desenvolvimento intelectual, cultural, educacional, psicossocial, afetivo, estético e lúdico".

Figura 2 - A proposta PBL-DT integrados para a formação das Soft Skills

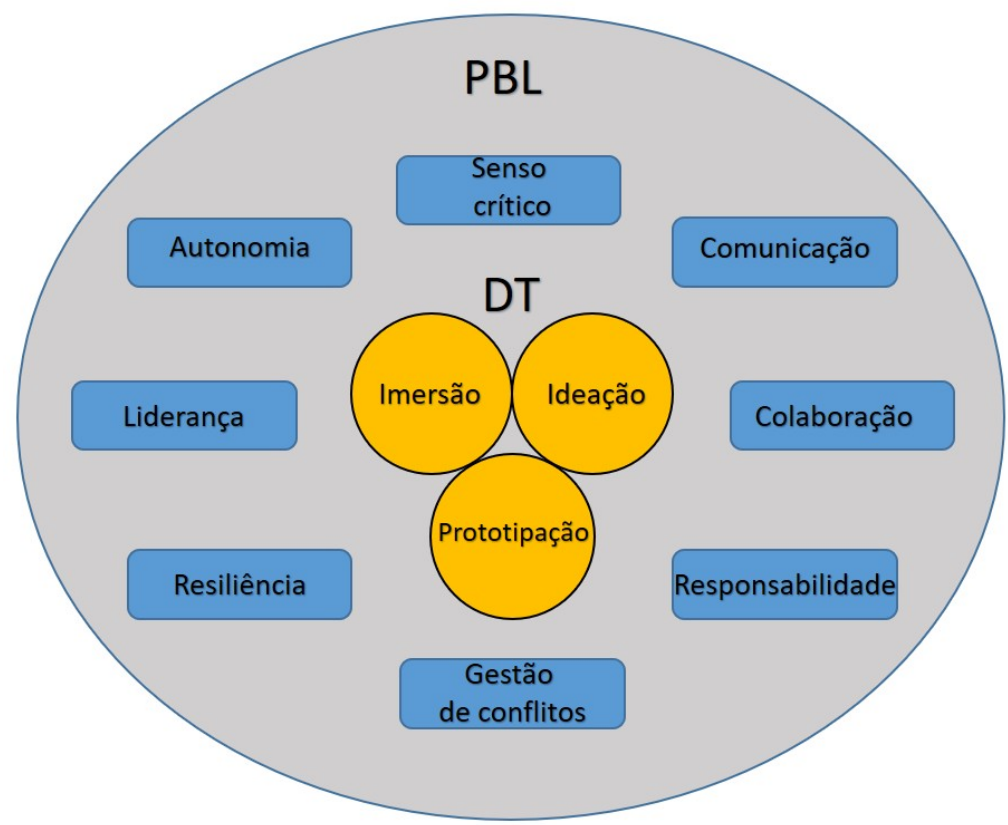

Fonte: Elaborado pelos autores

Portanto, a formação omnilateral dos sujeitos implica a integração dos aspectos fundamentais da vida como prática social. De acordo com Ramos (2008), esses aspectos são o trabalho, entendido como realização humana inerente ao ser e como prática econômica; a 
ciência, compreendida como os conhecimentos produzidos pela humanidade e que possibilita o contraditório avanço do capitalismo; e a cultura, que corresponde aos valores éticos e estéticos que direcionam as normas de conduta de uma sociedade.

De modo pragmático, a integração PBL-DT se deu num processo simbiótico, no qual a relação foi mutualmente vantajosa, onde os dois métodos foram beneficiados por esta integração. A PBL desenvolveu toda a organização geral do projeto, definindo suas etapas macro, ao longo de dez semanas, o conceito de mentoria no lugar de aulas, a opção pelo foco no estudante e em sua autonomia e protagonismo. A PBL trouxe também as avaliações formativas (BATISTA et al., 2007) semanais, na qual os grupos apresentavam a evolução dos projetos, e a apresentação final, que se coaduna também com a DT.

A DT trouxe a organização interna do projeto. Inserida no contexto da PBL, definiu etapas dentro do contexto do desenvolvimento do projeto em si, sustentadas na tríade imersão, ideação e prototipação, sem se desconectar da organização da PBL.

Com isto, o projeto LAPASSION teve todo o seu desenvolvimento pautado na proposta da PBL-DT integradas. Os resultados do projeto, apresentados a seguir, demonstram que esta foi uma opção com um grande potencial na formação humana integral.

\section{Resultados da PBL-DT no projeto LAPASSION}

O projeto LAPASSION Manaus teve como objetivo trabalhar em projetos que atendessem desafios propostos por empresas parceiras, com participantes de diversas nacionalidades e com conhecimentos multidisciplinares. Durante o projeto, foram trabalhadas as chamadas Soft Skills, com a orientação de mentores do IFAM e uma consultora especialista em Design Thinking para auxiliar no desenvolvimento de seis projetos.

No âmbito do projeto, se fez necessário uma formação inicial acerca das metodologias, que aconteceu bem antes da aplicação do projeto em si com os estudantes. A PBL já era uma metodologia conhecida por alguns professores e, portanto, uma oficina de dois dias foi utilizada para um nivelamento do conceito e entendimento de todos.

A primeira parte foi ministrada pelo coordenador do projeto, pesquisador e especialista em PBL, consolidando e nivelando conceitos, assim como estruturando de maneira macro as diretrizes para o projeto. A segunda parte deu ênfase à mentoria, necessária para o sucesso da DT/PBL e pouco usual aos professores. Esta parte foi ministrada pela Dra. Tiina Koskiranta, da University of Applied Science de Tampere (TAMK) da Finlândia, instituição parceira do projeto LAPASION. 
O DT foi trabalhado em três momentos: treinamento com os mentores, treinamento com os alunos participantes e aplicação no desenvolvimento dos projetos das equipes. Os treinamentos foram necessários para alinhar o conhecimento dos participantes, já que alguns desconheciam DT, e para delimitarmos os resultados a serem apresentados pelas equipes e o tempo necessário para a realização de cada fase no projeto.

Os mentores do projeto passaram por uma oficina de DT antes de iniciarem as mentorias com os alunos. O intuito foi nivelar os conhecimentos do time de professores e que eles passassem pela experiência de desenvolver um projeto utilizando o método DT.

A oficina durou cinco dias, com quatro horas por dia, e os mentores foram desafiados a pensarem em soluções com o mesmo tema que seria apresentado aos alunos participantes do projeto LAPASSION: "Tecnologias Socioambientais para a sustentabilidade da Amazônia".

A cada etapa do processo do DT (imersão, análise e síntese, ideação e prototipação), as equipes formadas apresentaram os resultados e observações sobre o entendimento de cada fase. Ao final, todos apresentaram os resultados de suas soluções propostas para os problemas anteriormente definidos, conforme apresentado na Figura 3.

Figura 3 - Oficina de DT com os mentores
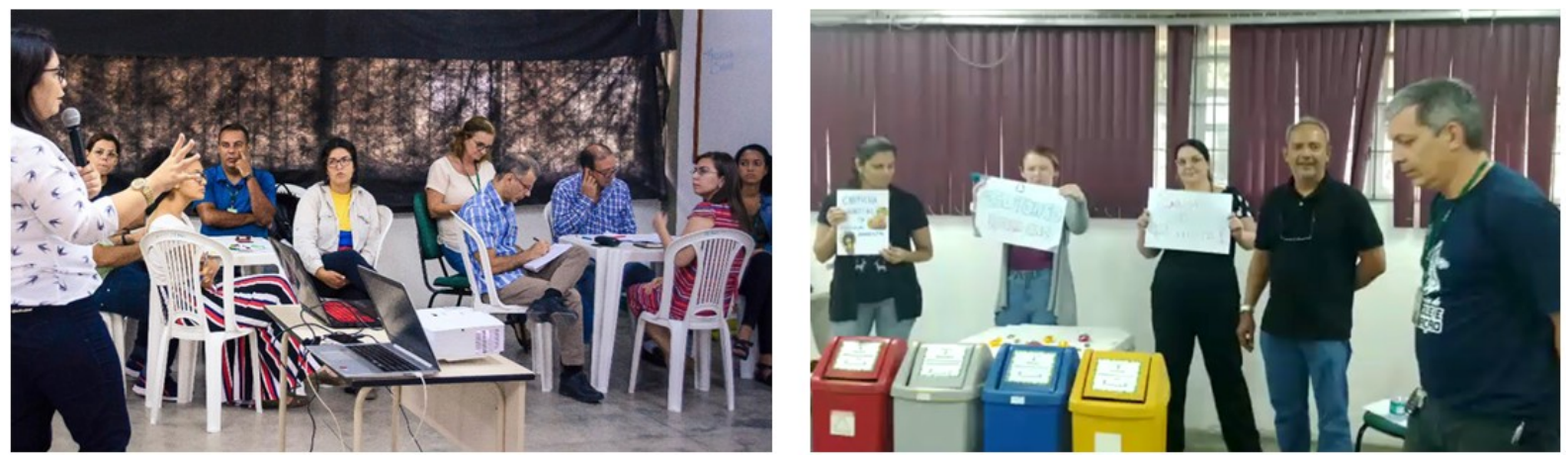

Fonte: Acervo dos autores

Ao passarem pela experiência de desenvolver soluções para problemas com o mesmo tema do projeto que iriam atuar como mentores, estes perceberam os pontos mais complexos do processo e puderam, ao orientar, compreender melhor as dúvidas dos alunos.

$\mathrm{Na}$ primeira semana do projeto, com a chegada dos alunos, foram apresentadas as diretrizes, objetivos do projeto e o cronograma das atividades. Também foi realizada uma oficina de DT com os alunos para apresentar o processo a ser utilizado no projeto. Durante três dias os alunos conheceram as etapas e os resultados que deveriam apresentar conforme o cronograma proposto para as dez semanas. 
Ao longo das dez semanas, os alunos trabalharam em equipe, resolveram conflitos e divergências de ideias, desenvolveram habilidades de comunicação, colaboração, resiliência, pensamento criativo, relacionamento interpessoal, liderança e ética. Aprenderam a resolver problemas complexos e a buscar conhecimentos específicos para atender as necessidades dos seis projetos.

Os times foram formados a fim de reunir alunos com conhecimentos complementares, a ter pelo menos um aluno estrangeiro e alunos locais que pudessem auxiliar na orientação e logística da cidade. A primeira atividade de imersão se deu em um fim de semana na Reserva de Desenvolvimento Sustentável do Rio Negro, na comunidade de Tumbira. Nesta os estudantes puderam conviver com a floresta, seus habitantes, os desafios, as soluções sustentáveis e, principalmente, se conhecerem melhor e criar elos afetivos que contribuíram para o desenvolvimento do projeto.

A Figura 4 apresenta as fases presenciais do projeto, como a imersão na reserva e as equipes se reunindo e sendo orientadas por mentores. Contudo, devido à pandemia SARS COV2 (COVID19), parte do projeto foi desenvolvida remotamente, utilizando, para tal, ferramentas online para encontros e discussões via webconferência.

Figura 4 - Desenvolvimento do projeto pelos alunos
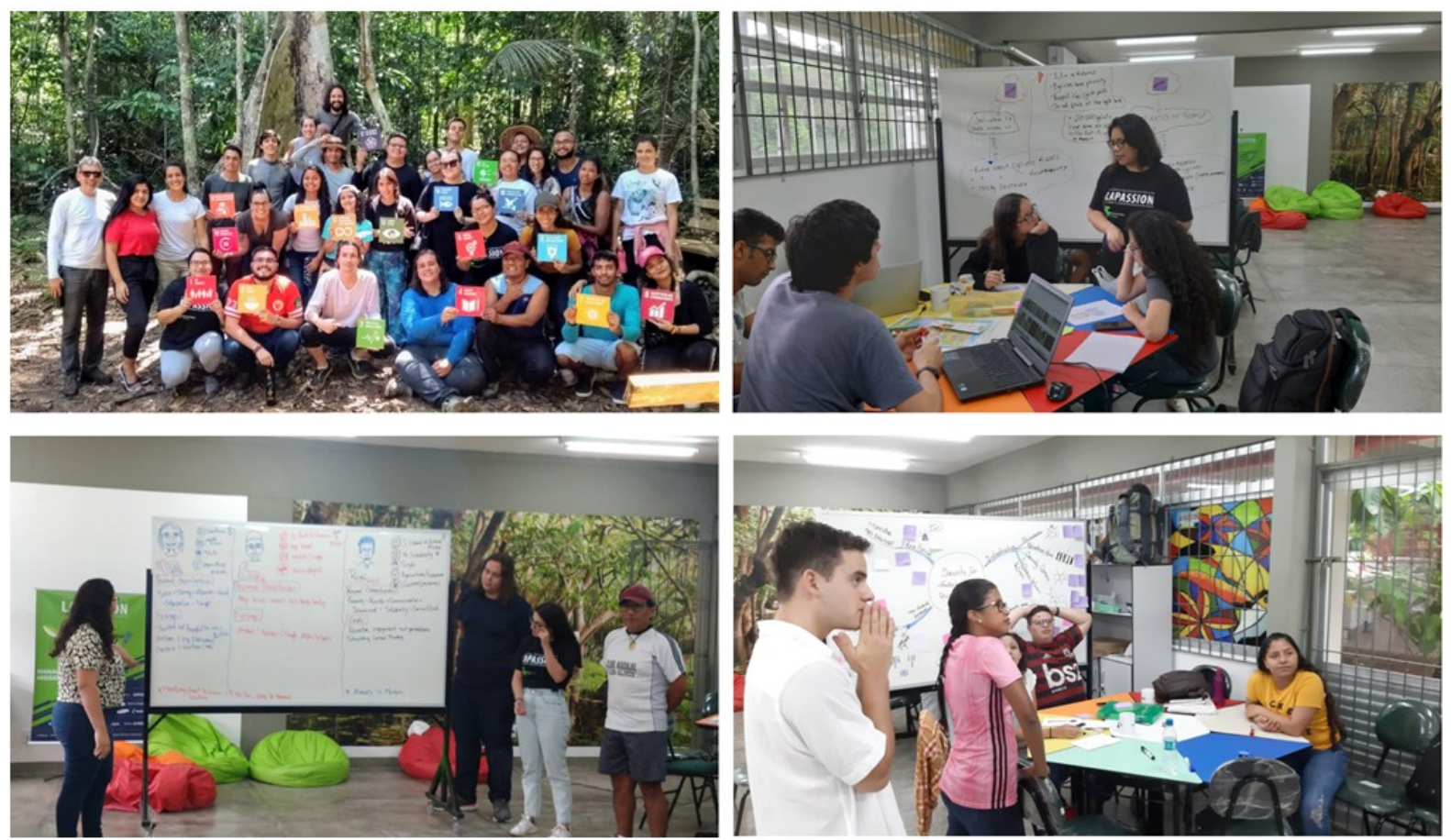

Fonte: Acervo dos autores 
A Figura 5 apresenta dois momentos deste período online, com a apresentação semanal dos alunos demonstrando a evolução dos projetos, e outro com as orientações dos mentores. Apesar das dificuldades impostas pela pandemia, a metodologia DT/PBL integrada se mostrou robusta e manteve o nível de motivação dos alunos, que desenvolveram suas habilidades de autonomia, responsabilidade e resiliência.

Figura 5 - Avaliações parciais e mentorias no período das atividades remotas
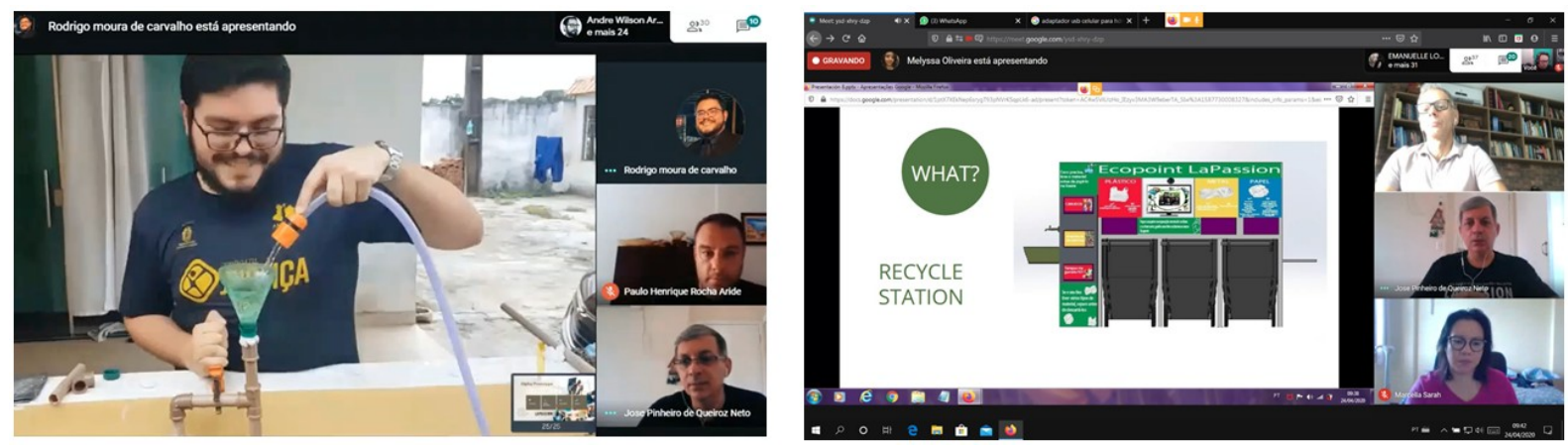

Fonte: Acervo dos autores

Quanto aos projetos desenvolvidos, o time um recebeu o desafio da empresa Caloi para desenvolver uma bicicleta sustentável. Como resultado, elaboraram uma proposta de substituir partes do produto por uma matéria prima alternativa. O time dois recebeu o desafio de elaborar um método para água potável do Instituto Transires. O resultado foi uma calha com filtros que coleta a água da chuva e fornece água potável. A Figura 6 apresenta uma ilustração do resultado final das equipes 1 e 2 , apresentado às empresas parceiras e comunidade acadêmica.

Figura 6 - Bike sustentável e filtro de água da chuva
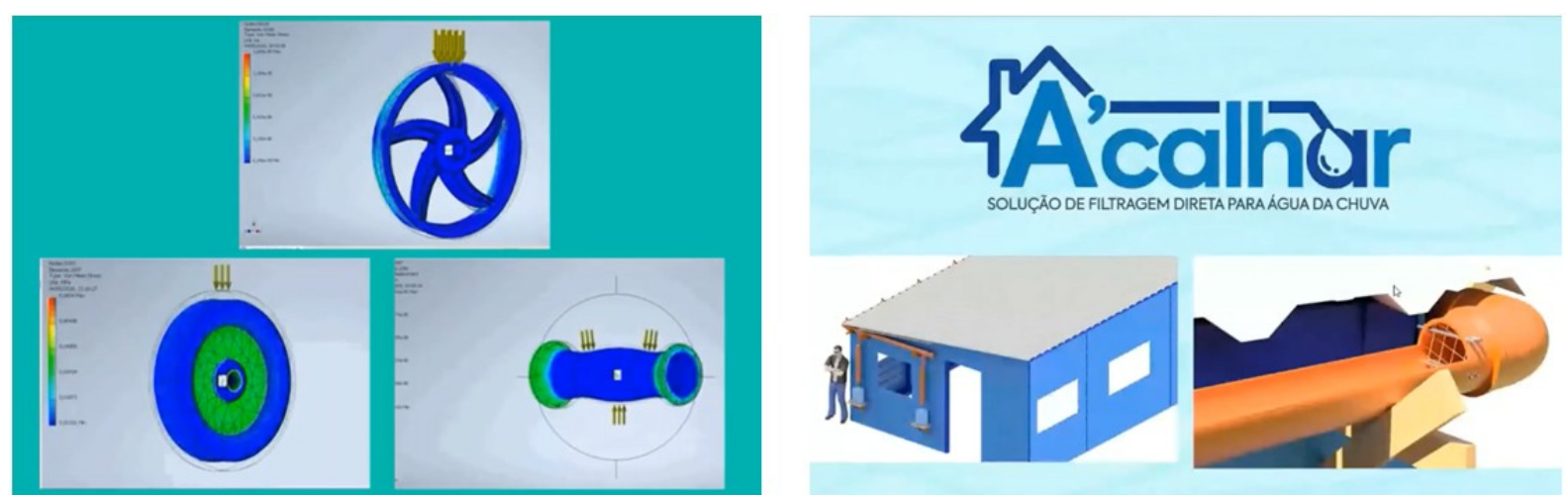

Fonte: Acervo dos autores 
O time três teve como desafio da empresa Samsung desenvolver uma solução para a reutilização de aparelhos eletrônicos. O resultado envolve o uso de Arduino e o uso de aparelhos celulares. O time quatro recebeu do próprio IFAM o desafio de propor uma solução para conscientizar os alunos e colaboradores sobre a reciclagem do lixo. Como produto final, foi elaborado um ecopoint que auxilia na separação dos resíduos. A Figura 7 apresenta uma ilustração do resultado final das equipes 3 e 4 , apresentado às empresas parceiras e comunidade acadêmica.

Figura 7 - Reuso de celular e Ecoponto
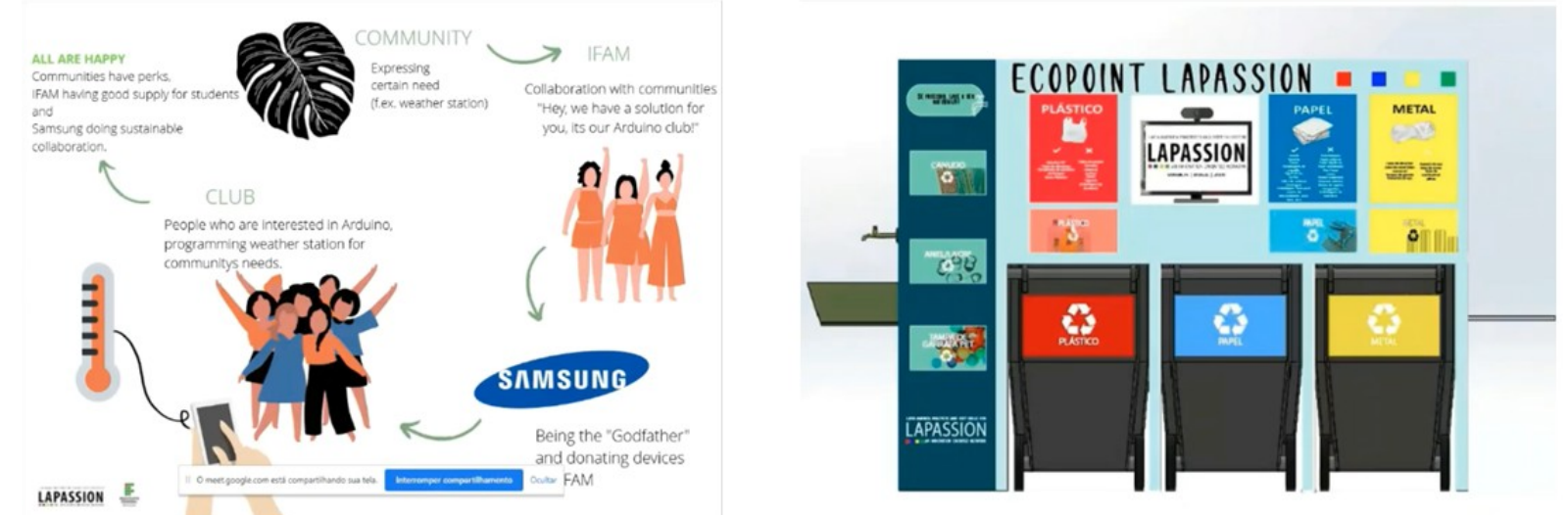

Fonte: Acervo dos autores

O time cinco recebeu o desafio da Secretaria do Estado do Meio Ambiente de trabalhar com a inserção de cadeias produtivas no mercado local. O resultado foi a elaboração de uma identidade visual com as características locais e que ressalta a cultura local para aplicação em produtos desenvolvidos pelas cadeias produtivas. O time seis recebeu o desafio da Fundação Amazônia Sustentável (FAS) de trabalhar com ensino remoto para comunidades. Como resultado, a proposta focou num protótipo de um aplicativo que compartilha o material elaborado pelos professores e que pode ser acessado por comunidades de difícil acesso. A Figura 8 apresenta uma ilustração do resultado final das equipes 5 e 6 , apresentado às empresas parceiras e comunidade acadêmica. 
Figura 8 - Produtos da floresta e Aplicativo para compartilhamento de aulas em comunidades
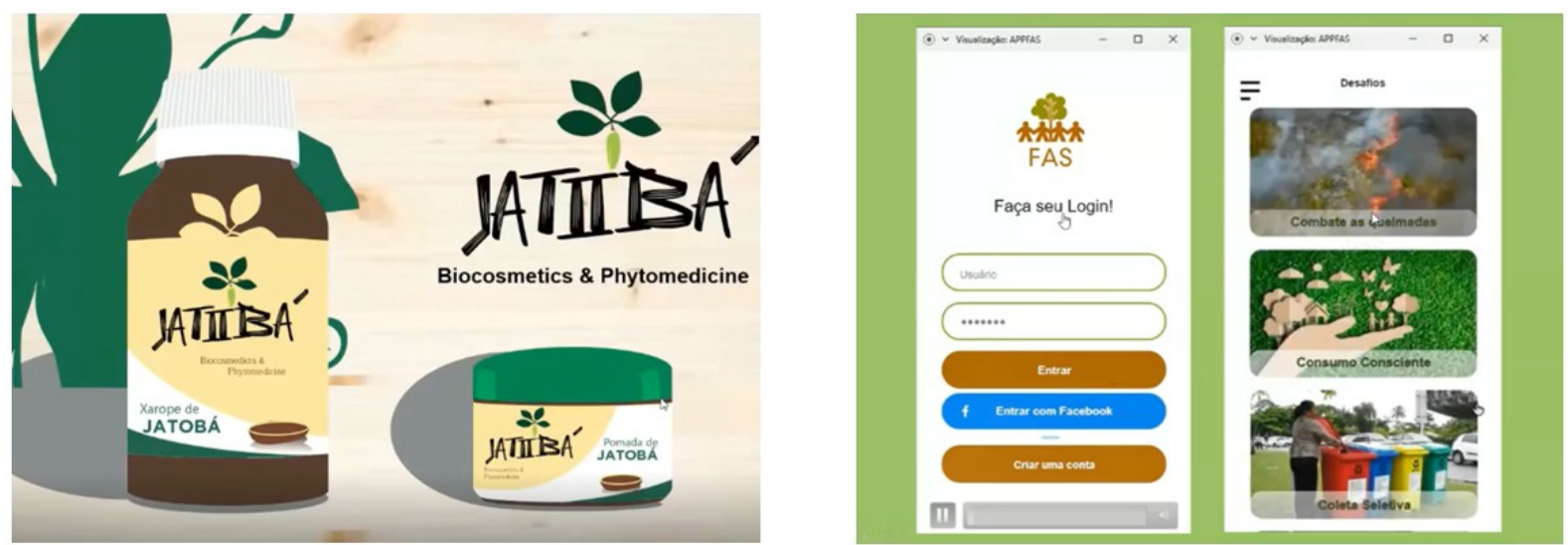

Fonte: Acervo dos autores

Todos os projetos foram apresentados no Demo Day ao final do projeto LAPASSION Manaus, que, por causa da pandemia, foi realizado de forma online. $\mathrm{O}$ site do projeto pode ser acessado no link: https://lapassionmanaus.wordpress.com/ onde estão descritas todas as fases do projeto, participantes, links para os projetos, relatório final de atividades e outros materiais elaborados ao longo da execução das atividades.

Ao término do projeto, dezessete alunos (60\% da turma) responderam voluntariamente a um questionário de avaliação do projeto e, principalmente, do quanto os mesmos perceberam que desenvolveram suas Soft Skills. O gráfico apresentado na Figura 9 demonstra que o PBL-DT teve sucesso em desenvolver as Soft Skills nos estudantes, sendo que a menor nota média foi obtida na habilidade "comunicação", o que já foi uma excelente nota, considerando que o projeto possuía estudantes dos idiomas nativos português, espanhol e finlandês, e que precisavam todos se comunicar em inglês.

Figura 9 - Nota média atribuída às Soft Skills adquiridas pela turma

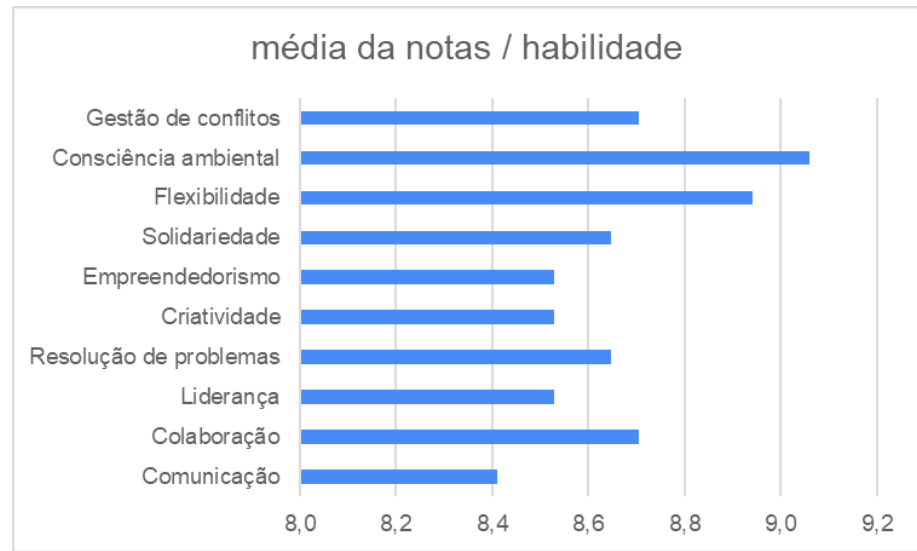

Fonte: Elaborado pelos autores

RIAEE - Revista Ibero-Americana de Estudos em Educação, Araraquara, v. 16, n. 3, p. 1791-1806, jul./set. 2021. e-ISSN: 1982-5587 
Individualmente, todos os alunos respondentes tiveram a percepção de melhoria nas Soft Skills, conforme apresentado no gráfico da Figura 10. Podemos observar que cinco estudantes tiveram próximo de $100 \%$ de aproveitamento, enquanto apenas três tiveram percepção abaixo de $80 \%$, sendo que o estudante com a menor percepção de desenvolvimento das Soft Skills foi de $60 \%$, o que significa que ainda há necessidade de acompanhamento individual, sem que haja perda de autonomia do estudante.

Figura 10 - Autopercepção das Soft Skills adquiridas por aluno

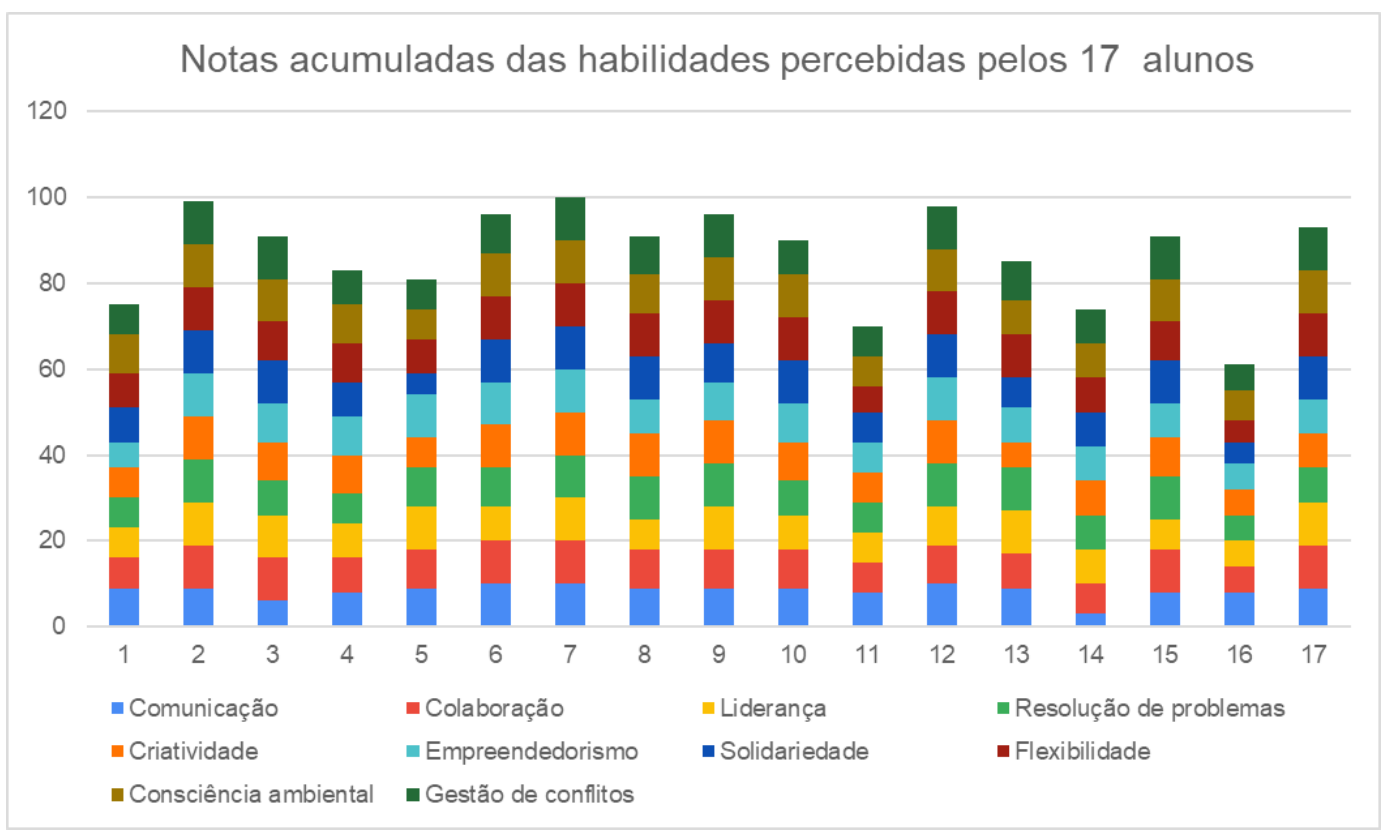

Fonte: Elaborado pelos autores

\section{Considerações finais}

Ao refletir sobre metodologias para o desenvolvimento das Soft Skills, que mantenham a liberdade e o ambiente necessário à autonomia e protagonismo dos estudantes, sem perder o foco e com uma maneira organizada de estruturar o pensamento inovativo, para um melhor desenvolvimento do processo e de seu resultado final, entendemos a importância de integrar duas metodologias que, sinergicamente, alcancem este objetivo.

Utilizar duas metodologias consolidadas, como a PBL e o DT, extraindo o de melhor de cada uma delas em uma simbiose positiva, foi a grande contribuição deste trabalho. Adicionalmente, evidencia-se o necessário redimensionamento do papel do professor, que neste novo contexto não representa mais o detentor do saber e um verificador de aprendizagens, e sim um mentor que viabiliza um ambiente onde os estudantes são os protagonistas da aprendizagem. 
AGRADECIMENTOS: Os autores agradecem ao Programa ERASMUS PLUS/2017/UNIÃO EUROPÉIA, Acordo de Cooperação Internacional 585687-EPP-2017-1PT-EPPKA2-CBHE-JP, e à FAEPI (Fundação de Apoio ao Ensino, Pesquisa, Extensão e Interiorização do IFAM), pelo suporte ao projeto LAPASSION.

\section{REFERÊNCIAS}

BARBOSA, E.F; MOURA, D.G. Metodologias ativas de aprendizagem na Educação Profissional e Tecnológica. Tec. Senac, Rio de Janeiro, v. 39, n. 2, p. 48-67, maio/ago. 2013. Disponível em: http://www.bts.senac.br/index.php/bts/article/view/349. Acesso em: 02 maio 2019.

BATISTA, A. G. B. et al. Alfabetização e letramento: questões sobre avaliação. In: Próletramento: programa de formação continuada de professores dos anos/séries iniciais do ensino fundamental: alfabetização e linguagem. ed. rev. e ampl. Brasília, DF: Ministério da Educação, Secretaria da Educação Básica, 2007. 50 p.

BRASIL. Ministério da Educação. Secretária de Educação Profissional e Tecnológica. Políticas Públicas para a Educação Profissional e Tecnológica. Proposta em Discussão. Brasília, DF: MEC/SETEC, 2004. Disponível em: http://portal.mec.gov.br/setec/arquivos/pdf/ p_publicas.pdf. Acesso em: 10 out. 2020.

DINIZ, D. H. Pedagogia por projeto influência do uso da técnica no aproveitamento acadêmico dos alunos do Ensino Médio do Colégio São Paulo de Belo Horizonte, MG. 2015. 139 f. Dissertação (Mestrado) - Pontifícia Universidade Católica de Minas Gerais, 2015.

FRIGOTTO, G. Educação omnilateral. In: CALDART, R. S. et al. Dicionário da Educação do Campo. Rio de Janeiro, São Paulo: Expressão Popular, 2012.

MARQUES, S. K. J. Aprendendo com PBL: Experiência de Aplicação do PBL no curso de engenharia civil do IFAL - Palmeira dos Índios. Writers and Tampere University of Applied Sciences. Tempere, 2016. Disponível em:

http://julkaisut.tamk.fi/PDF-tiedostot-web/Muut/Finnish-education-meets-Braziliancreativity.pdf. Acesso em: 20 nov. 2020.

MASSON, T. J. et al. Metodologia de ensino: Aprendizagem Baseada em Projetos (PBL). In: CONGRESSO BRASILEIRO DE EDUCAÇÃO EM ENGENHARIA, 2012, Belém. Anais [...]. Belém, 2012. Disponível em:

http://www.abenge.org.br/cobenge/arquivos/7/artigos/104325.pdf. Acesso em: 10 nov. 2020.

QUEIROZ-NETO, J. P. et al. Using modern pedagogical tools to improve learning in technological contents. In: FRONTIERS IN EDUCATION CONFERENCE (FIE), 2015, El Paso. Proceedings [...]. El Paso, TX, 2015. p. 1-8. DOI: 10.1109/FIE.2015.7344383

RAMOS, M. N. Concepção do ensino médio integrado. Texto apresentado em seminário promovido pela Secretaria de Educação do Estado do Pará, 2008. v. 8. Disponível em 
https://tecnicadmiwj.files.wordpress.com/2008/09/textoconcepcao-do-ensino-mediointegrado-marise ramos1.pdf. Acesso em: 10 dez. 2020.

STAHNKE, F. et al. Aprendizagem Baseada em Projetos: o caso Health Simulator. Revista TEKNOS, v. 15, n. 2, p. 39-48, 2015. Disponível em: https://revistas-

tecnologicocomfenalco.info/index.php/teknos/article/view/491. Acesso em: 10 nov. 2020.

VIANNA, M. Design thinking: inovação em negócios. Design Thinking, 2012.

ZABALA, A. A prática educativa: como ensinar. Porto Alegre: ArtMed, 1998.

\section{Como referenciar este artigo}

QUEIROZ-NETO, J. P.; FARIAS, M. S. F.; CHAGAS, E. L. T. Project Based Learning e Design Thinking em um projeto de intercâmbio. Revista Ibero-Americana de Estudos em Educação, Araraquara, v. 16, n. 3, p. 1791-1806, jul./set. 2021. e-ISSN: 1982-5587. DOI: https://doi.org/10.21723/riaee.v16i3.14557

Submetido em: 19/08/2020

Revisões requeridas em: 15/09/2020

Aprovado em: $10 / 10 / 2020$

Publicado em: 01/07/2021 